\title{
The 5-factor modified frailty index: an effective predictor of mortality in brain tumor patients
}

\author{
Adham M. Khalafallah, MD, Sakibul Huq, BS, Adrian E. Jimenez, BS, Henry Brem, MD, and \\ Debraj Mukherjee, MD, MPH
}

Department of Neurosurgery, Johns Hopkins University School of Medicine, Baltimore, Maryland

\begin{abstract}
OBJECTIVE Health measures such as the Charlson Comorbidity Index (CCI) and the 11-factor modified frailty index ( $\mathrm{mFI}-11$ ) have been employed to predict general medical and surgical mortality, but their clinical utility is limited by the requirement for a large number of data points, some of which overlap or require data that may be unavailable in large datasets. A more streamlined 5 -factor modified frailty index ( $\mathrm{mFI}-5$ ) was recently developed to overcome these barriers, but it has not been widely tested in neuro-oncology patient populations. The authors compared the utility of the $\mathrm{mFI}-5$ to that of the $\mathrm{CCl}$ and the $\mathrm{mFl}-11$ in predicting postoperative mortality in brain tumor patients.

METHODS The authors retrospectively reviewed a cohort of adult patients from a single institution who underwent brain tumor surgery during the period from January 2017 to December 2018. Logistic regression models were used to quantify the associations between health measure scores and postoperative mortality after adjusting for patient age, race, ethnicity, sex, marital status, and diagnosis. Results were considered statistically significant at $p$ values $\leq 0.05$. Receiver operating characteristic (ROC) curves were used to examine the relationships between $\mathrm{CCl}, \mathrm{mFI}-11$, and $\mathrm{mFI}-5$ and mortality, and DeLong's test was used to test for significant differences between c-statistics. Spearman's rho was used to quantify correlations between indices.
\end{abstract}

RESULTS The study cohort included 1692 patients (mean age 55.5 years; mean CCl, mFl-11, and mFI- 5 scores 2.49 , 1.05 , and 0.80 , respectively). Each 1-point increase in $\mathrm{mFI}-11$ (OR 4.19, $p=0.0043$ ) and $\mathrm{mFI}-5(\mathrm{OR} 2.56, p=0.018$ ) scores independently predicted greater odds of 90 -day postoperative mortality. Adjusted $\mathrm{CCl}, \mathrm{mFI}-11$, and $\mathrm{mFI}-5 \mathrm{ROC}$ curves demonstrated c-statistics of 0.86 ( $\mathrm{Cl} 0.82-0.90), 0.87$ ( $\mathrm{Cl} 0.83-0.91$ ), and 0.87 ( $\mathrm{Cl} 0.83-0.91$ ), respectively, and there was no significant difference between the c-statistics of the adjusted $\mathrm{CCl}$ and the adjusted $\mathrm{mFI}-5$ models $(p=$ 0.089 ) or between the adjusted mFI-11 and the adjusted mFI-5 models $(p=0.82)$. The 3 indices were well correlated ( $p$ $<0.01$ ).

CONCLUSIONS The adjusted $\mathrm{mFI}-5$ model predicts 90 -day postoperative mortality among brain tumor patients as well as our adjusted $\mathrm{CCl}$ and adjusted $\mathrm{mFI}-11$ models. The simplified $\mathrm{mFI}-5$ may be easily integrated into clinical workflows to predict brain tumor surgery outcomes in real time.

https://thejns.org/doi/abs/10.3171/2020.5.JNS20766

KEYWORDS frailty; oncology; outcomes

$\Lambda$ MPLE research has been directed toward developing methods of predicting mortality and other outcomes among patients based upon existing comorbidities and other factors, including age and functional status. ${ }^{1-13}$ This line of investigation has led to the development of frailty indices, which relate accrued deficits and comorbidities in patients to risks of short- and long-term complications and death. ${ }^{11}$

The Charlson Comorbidity Index (CCI) and 11-factor modified frailty index (mFI-11) are well-validated health measures that have been applied within general medical and surgical datasets to retrospectively stratify patients based on their risks for the development of posttreatment complications and mortality. ${ }^{1-17}$ Use of these measures requires eliciting specific patient history elements and assigning associated point values to each element in order to generate a composite score. Created in 1987 by Mary E. Charlson, the CCI incorporates the use of 19 separate health conditions on a 1- to 6-point scale (minimum score 0, maximum score 37) to develop a composite score (Table

ABBREVIATIONS AUC = area under the ROC curve; $\mathrm{CCI}=$ Charlson Comorbidity Index; EHR = electronic health record; KPS = Karnofsky Performance Status; $\mathrm{mFI}-5=$ 5 -factor modified frailty index; $\mathrm{mFI}$-11 = 11-factor modified frailty index; NSQIP = National Surgical Quality Improvement Program; ROC = receiver operating characteristic; $\mathrm{sICH}=$ spontaneous intracerebral hemorrhage.

SUBMITTED March 11, 2020. ACCEPTED May 11, 2020.

INCLUDE WHEN CITING Published online August 14, 2020; DOI: 10.3171/2020.5.JNS20766. 
TABLE 1. Comparison of the components of the CCl, $\mathrm{mFI}-11$, and $\mathrm{mFI}-5$

\begin{tabular}{lcc}
\hline \multicolumn{1}{c}{ CCl (score weight) } & mFl-11 & mFI-5 \\
\hline AIDS (6) & Functional status & Functional status \\
\hline Metastatic solid tumor (6) & History of diabetes & History of diabetes \\
\hline Moderate or severe liver disease (3) & Respiratory problems & History of COPD \\
\hline Lymphoma (2) & Congestive heart failure & Congestive heart failure \\
\hline Leukemia (2) & Arterial hypertension & Hypertension \\
\hline Any tumor (2) & Cardiac problems & - \\
\hline Diabetes with end-organ damage (2) & Myocardial infarction & - \\
\hline Moderate or severe renal disease (2) & Delirium & - \\
\hline Hemiplegia (2) & History related to cognitive impairment or loss & - \\
\hline Diabetes (1) & Cerebrovascular problems & - \\
\hline Mild liver disease (1) & History of stroke or decreased peripheral pulses & - \\
\hline Ulcer disease (1) & - & - \\
\hline Connective tissue disease (1) & - & - \\
\hline Chronic pulmonary disease (1) & - & - \\
\hline Dementia (1) & - & - \\
\hline Cerebrovascular disease (1) & - & - \\
\hline Peripheral vascular disease (1) & - & - \\
\hline Congestive heart failure (1) & - & - \\
\hline Myocardial infarction (1) & - & - \\
\hline Age (+1 each decade $\geq 50$ yrs) & - & - \\
\hline
\end{tabular}

* Functional status score: 1 = requiring assistance with activities of daily living; 0 = not requiring assistance.

1). For example, "diabetes with end-organ damage" and "hemiplegia" are each assigned 2 points within the CCI scoring system. ${ }^{18}$

The mFI-11 was created in 2012 in an attempt to create a more simplified risk stratification tool. In contrast to the CCI, each element of the mFI-11 accounts for only 1 point. Additionally, the mFI-11 includes some physical examination findings, such as "decreased peripheral pulses." Furthermore, several elements within the mFI-11 seemingly clinically overlap, including "respiratory problems" with "congestive heart failure," "cardiac problems" with "myocardial infarction," and "delirium" with "history related to cognitive impairment or loss" (Table 1).

Although these indices have demonstrated promising utility for clinical use, it remains time-consuming to elicit the necessary data elements in real time, and calculations of weighted elements specifically for the CCI are not intuitive or expeditious in the clinical setting. As a result, there has been limited clinical adoption of these tools, which has promoted increasing interest in creating and validating a simple, clinic-friendly tool capable of predicting important posttreatment outcomes in surgical patients.

In an attempt to address this need for a simpler health measurement tool, the simplified 5-factor modified frailty index (mFI-5) was recently introduced and validated within the general surgery literature. ${ }^{6}$ The mFI-5 includes 5 nonoverlapping clinical conditions, namely functional status, history of diabetes, history of chronic obstructive pulmonary disease, congestive heart failure, and hypertension, which are all characterized during routine clinic visits. Each condition is assigned a 1-point value, for a minimum score of 0 and a maximum score of 5. Importantly, this tool does not include any physical examination elements. An mFI-5 score $\geq 1$ has been associated with high rates of patient morbidity and mortality in the surgical literature..$^{2,7}$

The primary goal of this study was to perform what was to our knowledge the first comparative analysis of the predictive capabilities of the CCI, mFI-11, and mFI-5 in brain tumor patients. Identifying a small subset of preoperative factors significantly correlated with short- and longer-term outcomes vis-à-vis the mFI-5 may be clinically useful to help risk stratify those primary brain tumor patients for whom neurosurgical intervention is being considered.

\section{Methods \\ Patient Selection and Recorded Variables}

We conducted our study using a cohort of 1925 adult (age $\geq 18$ years) patients who were operated on for brain tumors at a single institution between January 1, 2017, and December 31, 2018. After only including cases in which patients were undergoing their first brain tumor surgery (repeat surgeries were excluded), our cohort size decreased to 1692 patients. Our IRB, acting as a HIPAA Privacy Board, reviewed and approved the waiver of informed consent for this retrospective, HIPAA-compliant study (IRB00209855). Variables collected for this study by the Center for Clinical Data Analysis at our institution included patient age, race and ethnicity, sex, marital status, and mortality. Each patient's diagnosis and preoperative 
Karnofsky Performance Status (KPS) score were verified using manual chart review of electronic health records (EHRs).

CCI, mFI-11, and mFI-5 scores were calculated for each patient. There were no patients in our cohort who had missing medical comorbidity data, and therefore we were able to calculate CCI, mFI-5, and mFI-5 scores for all 1692 patients. Table 1 displays the various factors comprising the CCI, $\mathrm{mFI}-11$, and $\mathrm{mFI}-5$. We derived these factors from a clinical institutional database created using the ICD-10 codes, which were extracted from the EHR system. Notably, the CCI scores were calculated as a weighted index (1-6 points), meaning that specific comorbidities (e.g., AIDS or metastatic solid tumor) contribute more to the final value of the index. In contrast, for each factor within the mFI-11 and mFI-5, a score of 1 indicates that the patient has the comorbidity and a score of 0 indicates the patient does not have the comorbidity. For functional status, 0 was defined as requiring no assistance with daily living and 1 was defined as requiring any assistance. ${ }^{6} \mathrm{~A}$ total score was obtained for each index by summation of these numbers. Patients were stratified according to the median CCI, mFI-11, and mFI-5 scores. In this study, 90day postoperative mortality was defined as any patient death within 90 days of the initial hospital admission associated with surgery.

\section{Statistical Analysis}

Statistical analyses were conducted using SPSS version 25 (IBM Corp.). Fisher's exact test was used for bivariate analysis of categorical variables, the independent-samples t-test was used to compare continuous variables, and Levene's test was used to compare the variance of continuous variables calculated for 2 groups. Spearman's rho was used to quantify correlations between indices. Logistic regression models were used for multivariate analyses of CCI, $\mathrm{mFI}-11$, and $\mathrm{mFI}-5$ effectiveness in predicting patient mortality. Receiver operating characteristic (ROC) curves were generated for both unadjusted and adjusted logistic regression models. The c-statistic, also known as the area under the ROC curve (AUC), was calculated for each ROC curve. DeLong's test was used to compare the predictive ability of different models. The Hosmer-Lemeshow test using 10 groups was used to assess model goodness of fit, with a test result of $p<0.05$ indicating lack of goodness of fit. Statistical significance was defined as $\mathrm{p}<0.05$.

\section{Results}

\section{Patient Demographics}

Various demographic characteristics of our 1692 patients are detailed in Table 2. The mean age \pm SD of our patients was $55.5 \pm 15.22$ years. The majority were women (52.3\%), White/Caucasian (69.9\%), and married (65.5\%). The mean CCI, mFI-11, and mFI-5 scores were $2.39 \pm$ $1.86,1.05 \pm 1.19$, and $0.80 \pm 0.84$, respectively. Meningiomas $(n=431,25.5 \%)$ were the largest subset of primary brain tumors operated on within our cohort, followed by high-grade gliomas $(\mathrm{n}=319,18.9 \%)$ and pituitary tumors $(n=263,15.5 \%)$. Nine $(0.5 \%)$ patients died during their hospital admission, 15 (0.9\%) died within 30 days of dis-
TABLE 2. Patient demographics $(n=1692)$

\begin{tabular}{|c|c|}
\hline Variable & Value \\
\hline Mean age, yrs & $55.49 \pm 15.22$ \\
\hline \multicolumn{2}{|l|}{ Sex } \\
\hline Female & $885(52.3)$ \\
\hline Male & $807(47.7)$ \\
\hline \multicolumn{2}{|l|}{ Race } \\
\hline White or Caucasian & $1182(69.9)$ \\
\hline Black or African American & $282(16.7)$ \\
\hline Other & $228(13.5)$ \\
\hline \multicolumn{2}{|l|}{ Ethnicity } \\
\hline Not Hispanic or Latino & $1581(93.4)$ \\
\hline Hispanic or Latino & $79(4.7)$ \\
\hline Patient refused to answer & $13(0.8)$ \\
\hline Unknown & $19(1.1)$ \\
\hline \multicolumn{2}{|l|}{ Marital status } \\
\hline Married & $1109(65.5)$ \\
\hline Single & $356(21.0)$ \\
\hline Divorced & $123(7.3)$ \\
\hline Widowed & $90(5.3)$ \\
\hline Unknown & $14(0.9)$ \\
\hline \multicolumn{2}{|l|}{ Mean score indices (median) } \\
\hline $\mathrm{CCl}$ & $2.39 \pm 1.86(2)$ \\
\hline $\mathrm{mFl}-11$ & $1.05 \pm 1.19(1)$ \\
\hline $\mathrm{mFl}-5$ & $0.80 \pm 0.84(1)$ \\
\hline Mean KPS score & $80.70 \pm 16.33$ \\
\hline
\end{tabular}

Values are presented as number of patients (\%) or mean \pm SD unless otherwise indicated.

charge, and 29 (1.7\%) died within 31-90 days of discharge. Therefore, among the patients in our cohort, there were $53(3.1 \%)$ total cases of 90-day postoperative mortality. Table 3 displays the incidence of postoperative mortality for different types of brain tumor diagnoses found within our patient cohort. Patients with brain metastases demonstrated the highest total 90 -day postoperative mortality (n $=30,1.8 \%)$.

\section{Bivariate Analyses of Demographics and Index Scores Upon 90-Day Postoperative Mortality}

We first analyzed the number of 90-day postoperative mortality cases for each of the demographic variables that we collected for our patients in bivariate analyses. The mean age of patients who did not experience 90 -day postoperative death was 55.22 years, while the mean age of patients who did experience 90 -day postoperative death was 64.06 years. The mean age of patients who died postoperatively was significantly higher than that of their counterparts who did not die $\left(\mathrm{p}=4.30 \times 10^{-5}\right)$. Additionally, there were $36(4.5 \%)$ cases of 90-day postoperative mortality among 807 men compared to 17 (1.9\%) cases among 885 women. In our cohort, men had a significantly higher incidence of 90-day postoperative mortality than women (OR 2.38, $\mathrm{p}=0.0031)$. There was no statistically 
TABLE 3. Diagnoses and postoperative mortality rates $(n=1692)$

\begin{tabular}{|c|c|c|c|c|c|c|}
\hline Diagnosis & $\begin{array}{l}\text { Total No. of } \\
\text { Patients }\end{array}$ & $\begin{array}{l}\text { Death During } \\
\text { 1st Admission }\end{array}$ & $\begin{array}{l}\text { Death w/in } 30 \text { Days } \\
\text { of } 1 \text { st Discharge }\end{array}$ & $\begin{array}{c}\text { Death w/in 31-90 } \\
\text { Days of 1st Discharge }\end{array}$ & $\begin{array}{l}\text { Total Deaths w/in } 90 \\
\text { Days of Admission }\end{array}$ & $\begin{array}{l}\text { Total Alive } 90 \text { Days } \\
\text { After } 1 \text { st Admission }\end{array}$ \\
\hline Meningioma & $431(25.5)$ & $0(0.0)$ & $1(0.06)$ & $1(0.06)$ & $2(0.1)$ & $429(25.4)$ \\
\hline High-grade glioma & $319(18.9)$ & $2(0.1)$ & $4(0.2)$ & $8(0.5)$ & $14(0.8)$ & $305(18.0)$ \\
\hline Pituitary tumor & $263(15.5)$ & $0(0.0)$ & $1(0.06)$ & $0(0.0)$ & $1(0.06)$ & $262(15.5)$ \\
\hline Brain metastasis & $226(13.4)$ & $4(0.2)$ & $8(0.5)$ & $18(1.1)$ & $30(1.8)$ & $196(11.6)$ \\
\hline Other & $173(10.2)$ & $3(0.2)$ & $1(0.06)$ & $0(0.0)$ & $4(0.2)$ & $169(10.0)$ \\
\hline Vestibular schwannoma & $144(8.5)$ & $0(0.0)$ & $0(0.0)$ & $1(0.06)$ & $1(0.06)$ & $143(8.5)$ \\
\hline Low-grade glioma & $136(8.0)$ & $0(0.0)$ & $0(0.0)$ & $1(0.06)$ & $1(0.06)$ & $135(8.0)$ \\
\hline
\end{tabular}

Values are presented as number of patients (\%).

significant difference in 90-day postoperative mortality as a function of patient race $(p=0.57)$, ethnicity $(p=0.51)$, or marital status $(\mathrm{p}=0.46)$

The predictive ability of each frailty index was then analyzed by bivariate analyses containing CCI, mFI-11, or mFI-5 as the sole independent variable and with 90day patient mortality serving as the dependent variable. In these bivariate analyses, CCI (OR 4.03, $\left.\mathrm{p}=5.09 \times 10^{-5}\right)$, mFI-11 (OR 4.11, $\left.\mathrm{p}=4.0 \times 10^{-5}\right)$, and mFI-5 (OR 2.29, $\mathrm{p}=$ $0.00061)$ were all significant predictors of mortality. Next, we assessed 90-day postoperative mortality as a function of dichotomized CCI, mFI-11, and mFI-5 scores according to the median. The median CCI, mFI-11, and mFI-5 scores were 2,1 , and 1 , respectively. There were $6(0.9 \%)$ cases of 90-day postoperative mortality among 656 patients with a CCI of $<2$ and $47(4.5 \%)$ cases of postoperative mortality among 1036 patients with a CCI of $\geq 2$. In bivariate analysis, patients with $\mathrm{CCI} \geq 2$ demonstrated significantly higher 90-day postoperative mortality relative to their counterparts $\left(\mathrm{OR} 5.14, \mathrm{p}=1.05 \times 10^{-5}\right)$. There were $5(0.8 \%)$ cases of 90 -day postoperative mortality among 656 patients with an mFI-11 score of 0 and $48(4.6 \%)$ cases of 90-day postoperative mortality among 1036 patients with an mFI-11 score $\geq 1$. In bivariate analysis, patients with mFI-11 scores $\geq 1$ demonstrated significantly higher 90-day postoperative mortality relative to their counterparts (OR 6.32, $\left.\mathrm{p}=2.12 \times 10^{-6}\right)$. There were $22(2.1 \%)$ cases of 90-day postoperative mortality among 1049 patients with an mFI-5 score of 0 and $31(4.8 \%)$ cases of 90day postoperative mortality among 643 patients with an $\mathrm{mFI}-5$ score $\geq 1$. In bivariate analysis, patients with $\mathrm{mFI}-5$ scores $\geq 1$ demonstrated significantly higher 90 -day postoperative mortality relative to their counterparts (OR 2.36, $\mathrm{p}=0.0024)$.

\section{Multivariate Analyses of Demographics and Index Scores Upon 90-Day Postoperative Mortality}

Next, adjusted logistic regression models were created using each index alongside the covariates of age, sex, race, ethnicity, marital status, and diagnosis upon 90-day postoperative mortality. For the CCI model, female sex (OR $0.51, p=0.032$ ) was associated with significantly decreased odds of 90-day postoperative mortality. Diagnoses of highgrade glioma (OR 0.35, $\mathrm{p}=0.0025)$, vestibular schwannoma (OR 0.076, $\mathrm{p}=0.013)$, meningioma $(\mathrm{OR} 0.038, \mathrm{p}=1.02$ $\left.\times 10^{-5}\right)$, pituitary tumor (OR $\left.0.029, \mathrm{p}=0.0064\right)$, low-grade glioma (OR 0.076, p = 0.013), or other tumor (OR 0.20, p $=0.0041)$ were all independently associated with a significantly decreased risk of 90-day postoperative mortality compared to a diagnosis of brain metastases. Notably, CCI score itself was not a significant predictor of 90-day mortality in multivariate analysis. When age was removed as a covariate from the logistic regression model, CCI score became a significant predictor of 90-day postoperative mortality (OR 2.52, $\mathrm{p}=0.045)$. For the mFI-11 model, an mFI-11 score $\geq 1$ (OR 4.19, $\mathrm{p}=0.0043$ ) was independently associated with increased odds of 90-day postoperative mortality, while diagnoses of high-grade glioma (OR 0.35, $p=0.0029)$, vestibular schwannoma (OR 0.071, $p=0.010)$, meningioma $\left(\mathrm{OR} 0.036, \mathrm{p}=7.12 \times 10^{-6}\right)$, pituitary tumor (OR 0.027, $\mathrm{p}=0.0047)$, low-grade glioma (OR 0.078, $\mathrm{p}=$ 0.014 ), and other tumor type (OR $0.20, p=0.0036$ ) were all independently associated with decreased odds of 90day postoperative mortality compared to a diagnosis of brain metastases. For the mFI-5 model, an mFI-5 score $\geq$ 1 (OR 2.56, $\mathrm{p}=0.0018$ ) and each 1-year increase in patient age $(\mathrm{OR} 1.03, \mathrm{p}=0.013)$ were associated with increased odds of 90-day postoperative mortality, while female sex (OR 0.50, $\mathrm{p}=0.029$ ) and diagnoses of high-grade glioma (OR 0.33, p = 0.0014), vestibular schwannoma (OR 0.061, $\mathrm{p}=0.0068)$, meningioma (OR 0.032, $\left.\mathrm{p}=3.65 \times 10^{-6}\right)$, pituitary tumor (OR 0.024, $\mathrm{p}=0.0031)$, low-grade glioma (OR 0.071, p = 0.010), and other tumor type (OR 0.18, p $=0.0023$ ) relative to a diagnosis of brain metastases were all significantly associated with decreased odds of 90-day postoperative patient mortality, as shown in Table 4. The CCI, mFI-11, and mFI-5 models had $\mathrm{p}$ values of $0.93,0.74$, and 0.88 , respectively, via the Hosmer-Lemeshow test, indicating goodness of fit for all 3 frailty index models.

\section{Statistical Comparison Between CCl, mFI-11, and mFI-5 Scores}

Correlations between the 3 indices within our patient population were calculated using Spearman's rho. The correlations between the mFI-11 and mFI-5, mFI-11 and CCI, and mFI-5 and CCI scores were 0.88, 0.55, and 0.47 , respectively. All correlations were statistically significant at a level of $\mathrm{p}<0.01$. Unadjusted ROC curves were created for the CCI, mFI-11, and mFI-5 scores, with Fig. 1 depicting these curves with a reference line and 
TABLE 4. Multivariate analysis of associations of frailty index types and demographic variables with total postoperative mortality

\begin{tabular}{|c|c|c|c|c|c|c|c|c|c|}
\hline \multirow[b]{3}{*}{ Variable } & \multicolumn{9}{|c|}{ Multivariate Analysis of 90-Day Postop Mortality } \\
\hline & \multicolumn{3}{|c|}{$\mathrm{CCl}$} & \multicolumn{3}{|c|}{$\mathrm{mFI}-11$} & \multicolumn{3}{|c|}{$\mathrm{mFl}-5$} \\
\hline & OR & p Value & $95 \% \mathrm{Cl}$ & OR & $p$ Value & $95 \% \mathrm{Cl}$ & OR & $p$ Value & $95 \% \mathrm{Cl}$ \\
\hline \multicolumn{10}{|l|}{ Index } \\
\hline $\mathrm{CCl}$ & 1.32 & 0.63 & $0.44-4.29$ & - & - & - & - & - & - \\
\hline $\mathrm{mFI}-11$ & - & - & - & 4.19 & $0.0043^{*}$ & $1.70-12.66$ & - & - & - \\
\hline $\mathrm{mFI}-5$ & - & - & - & - & - & - & 2.56 & $0.0018^{*}$ & $1.42-4.67$ \\
\hline Patient age, yrs & 1.03 & 0.050 & $1.00-1.06$ & 1.02 & 0.14 & $0.99-1.04$ & 1.03 & $0.013^{*}$ & $1.01-1.06$ \\
\hline \multicolumn{10}{|l|}{ Sex } \\
\hline Male & Ref & - & - & Ref & - & - & Ref & - & - \\
\hline Female & 0.51 & $0.032^{*}$ & $0.27-0.93$ & 0.55 & 0.062 & $0.29-1.02$ & 0.50 & $0.029^{*}$ & $0.26-0.92$ \\
\hline \multicolumn{10}{|l|}{ Race } \\
\hline White or Caucasian & Ref & - & - & Ref & - & - & Ref & - & - \\
\hline Black or African American & 1.67 & 0.18 & $0.76-3.44$ & 1.51 & 0.29 & $0.68-3.14$ & 1.74 & 0.15 & $0.79-3.63$ \\
\hline Other & 1.28 & 0.65 & $0.40-3.32$ & 1.34 & 0.59 & $0.42-3.51$ & 1.47 & 0.47 & $0.45-3.88$ \\
\hline \multicolumn{10}{|l|}{ Ethnicity } \\
\hline Hispanic or Latino & Ref & - & - & Ref & - & - & Ref & - & - \\
\hline Not Hispanic or Latino† & 1.71 & 0.63 & $0.29-32.89$ & 1.83 & 0.58 & $0.31-35.45$ & 2.20 & 0.48 & $0.36-43.30$ \\
\hline \multicolumn{10}{|l|}{ Marital status } \\
\hline Married & Ref & - & - & Ref & - & - & Ref & - & - \\
\hline Not married $\ddagger$ & 1.31 & 0.39 & $0.70-2.40$ & 1.27 & 0.44 & $0.68-2.34$ & 1.37 & 0.32 & $0.73-0.52$ \\
\hline \multicolumn{10}{|l|}{ Diagnosis } \\
\hline Brain metastases & Ref & - & - & Ref & - & - & Ref & - & - \\
\hline High-grade glioma & 0.35 & $0.0025^{\star}$ & $0.17-0.68$ & 0.35 & $0.0029^{*}$ & $0.17-0.69$ & 0.33 & $0.0014^{*}$ & $0.16-0.64$ \\
\hline Vestibular schwannoma & 0.076 & $0.013^{*}$ & $0.0042-0.38$ & 0.071 & $0.010^{*}$ & $0.0039-0.34$ & 0.061 & $0.0068^{*}$ & $0.0034-0.30$ \\
\hline Meningioma & 0.038 & $1.02 \times 10^{-5 *}$ & $0.0060-0.13$ & 0.036 & $7.12 \times 10^{-6 *}$ & $0.0057-0.12$ & 0.032 & $3.65 \times 10^{-6 *}$ & $0.0051-0.11$ \\
\hline Pituitary tumor & 0.029 & $0.0064^{*}$ & $0.0016-0.14$ & 0.027 & $0.00047^{*}$ & $0.0015-0.13$ & 0.024 & $0.00031^{*}$ & $0.0013-0.12$ \\
\hline Low-grade glioma & 0.20 & $0.0041^{*}$ & $0.058-0.54$ & 0.078 & $0.014^{*}$ & $0.0043-0.38$ & 0.071 & $0.010^{*}$ & $0.0039-0.35$ \\
\hline Other & 0.076 & $0.013^{*}$ & $0.0042-0.38$ & 0.20 & $0.0036^{*}$ & $0.057-0.53$ & 0.18 & $0.0023^{*}$ & $0.052-0.49$ \\
\hline
\end{tabular}

${ }^{*}$ Statistically significant $(p<0.05)$.

$\dagger$ Includes patients who are not Hispanic or Latino, patients who refused to answer, and patients with an unknown ethnicity.

$\ddagger$ Includes patients who are single, divorced, widowed, or have an unknown marital status.

with 90-day patient mortality serving as the dependent variable. The c-statistics (AUCs) for the unadjusted CCI, mFI-11, and mFI-5 curves were 0.67 (CI $0.63-0.70), 0.65$ (CI 0.61-0.69), and 0.61 (CI 0.54-0.67), respectively. Adjusted ROC curves were then created for all 3 indices, with the following covariates included in each logistic regression model alongside the index itself: age, sex, race, ethnicity, marital status, and diagnosis. Figure 2 depicts adjusted ROC curves for CCI, mFI-11, and mFI-5. The c-statistics for the adjusted CCI, mFI-11, and mFI-5 ROC curves were 0.86 (CI 0.82-0.90), 0.87 (CI 0.83-0.91), and 0.87 (CI 0.83-0.91), respectively. Using the DeLong test to compare the AUCs for the 3 frailty indices, we found that there was no significant difference when comparing any pair of the unadjusted ROC curves. While there was a significant difference between the adjusted AUCs of the CCI and mFI-11 ( $p=0.032)$, there was no significant difference between either of these 2 indices compared to the mFI-5 AUC.

\section{Discussion}

\section{Previous Research}

Charlson Comorbidity Index

There have been many prior studies aimed at determining factors predictive of complications and mortality among medical and surgical patients. A 1987 study by Charlson et al. introduced the Charlson Comorbidity Index (CCI), a weighted index used to predict mortality risk from comorbid diseases in a longitudinal study. ${ }^{18}$ The CCI has been applied within neurosurgery in an effort to risk stratify patients and better predict mortality based upon preexisting comorbidities. A 2011 study by Grossman et al. found that, among elderly patients with metastatic brain tumors, a higher CCI score (per incremental increase) was an important prognostic factor for greater hospital length of stay, higher total hospital charges, higher number of postoperative complications, and greater inpatient mortality. ${ }^{12}$ Nuño et al. found that a patient's CCI (per incremental increase) was significantly associated with increased oc- 


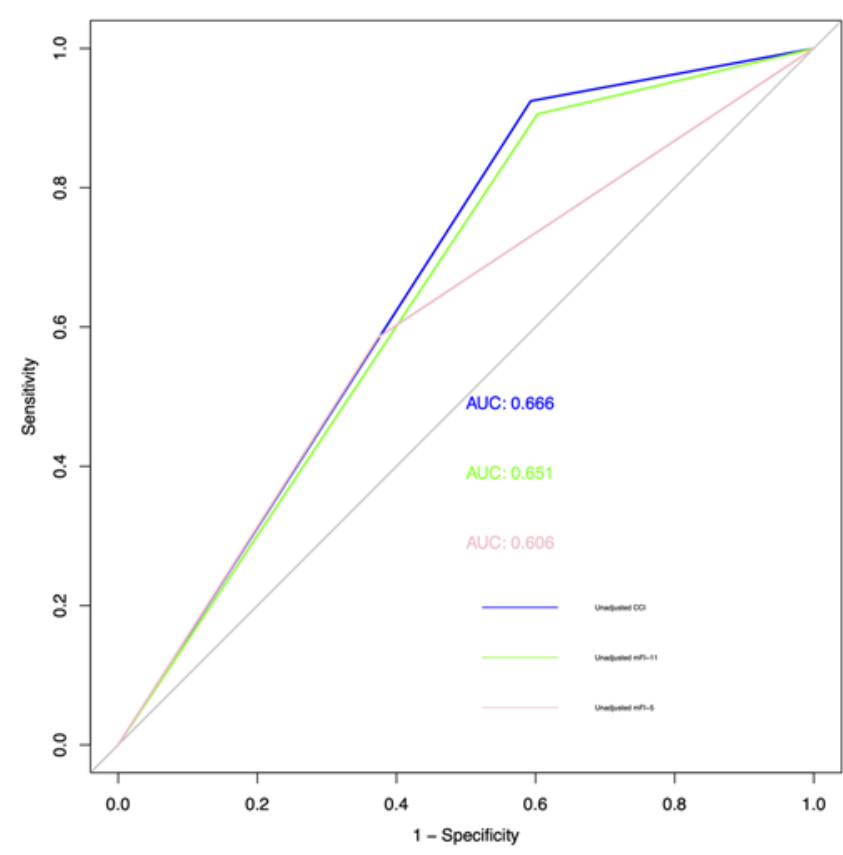

FIG. 1. Unadjusted ROC curves. The gray diagonal line corresponds to the reference curve. The blue curve corresponds to the $\mathrm{CCl}$. The green curve corresponds to the $\mathrm{mFI}-11$. The pink curve corresponds to the $\mathrm{mFI}-5$. Figure is available in color online only.

currence of in-hospital mortality $(\mathrm{p}<0.0001)$, patient safety indicators (metrics used to identify in-hospital patient safety events such as postoperative sepsis; $\mathrm{p}<0.0001$ ), and hospital-acquired conditions (undesired conditions arising during a hospital stay, such as catheter-associated urinary tract infection; $\mathrm{p}<0.0001) .{ }^{14}$ Ening and colleagues found that a CCI score $>3$, dichotomized according to the median, was significantly associated with poor progressionfree survival $(p<0.002)$ and overall survival $(p<0.0001)$ among glioblastoma patients; Ening et al. also found that patients older than 65 years demonstrated a greater proportion of comorbidities, manifesting as CCI scores $>3$ (p $<0.0001){ }^{1}$ Importantly, the present study utilizes a cohort of patients with a younger median age and a lower median CCI score compared to the cohort studied by Ening et al., explaining our choice of dichotomizing the $\mathrm{CCI}$ at a score of 2 rather than 3 .

\section{1-Factor Modified Frailty Index}

As described by Subramaniam et al., the mFI-11 was developed from efforts to abbreviate a 70-item frailty index originally developed by the Canadian Study of Health and Aging that had proved difficult to apply in clinical and research settings because many of its factors were either not regularly collected or difficult to measure in patients. ${ }^{6,19}$ A study by Imaoka et al. found that the mFI-11 was an effective predictor of postoperative outcomes among patients undergoing surgical intervention to treat spontaneous intracerebral hemorrhage (sICH), with a higher mFI-11 score (per incremental increase) being independently associated with mortality $6-8$ months after sICH $(\mathrm{p}<0.001) .{ }^{5}$ Studying a national cohort of patients from the American Col-

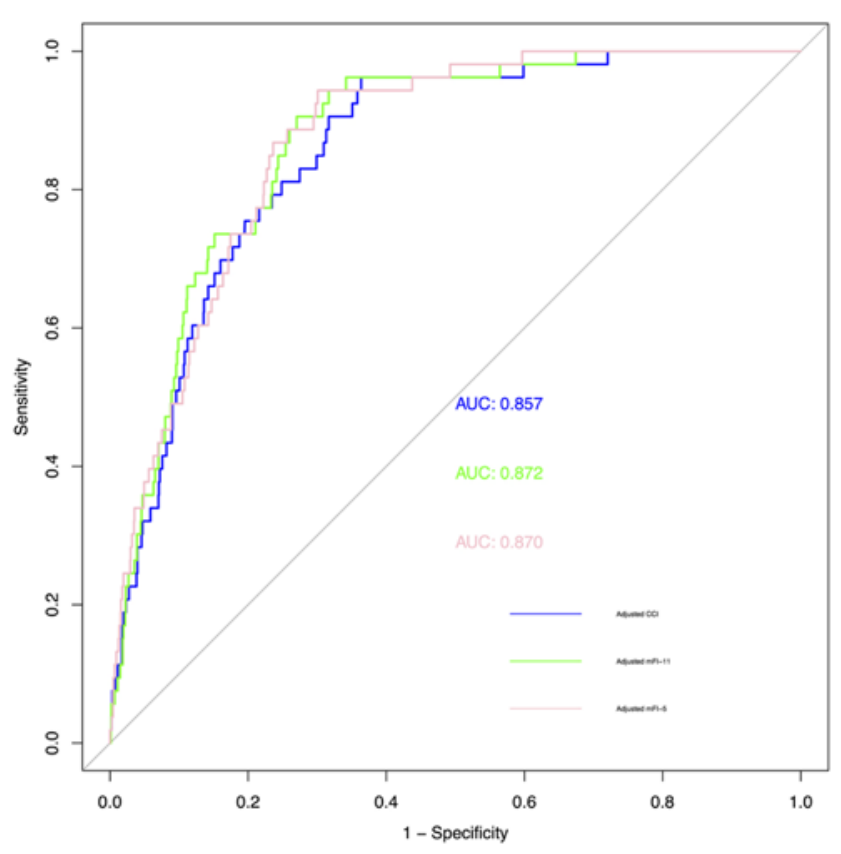

FIG. 2. ROC curves adjusted for age, sex, race, ethnicity, marital status, and diagnosis. The gray diagonal line corresponds to the reference curve. The blue curve corresponds to the $\mathrm{CCl}$. The green curve corresponds to the mFI-11. The pink curve corresponds to the $\mathrm{mFI}-5$. Figure is available in color online only.

lege of Surgeons National Surgical Quality Improvement Program (NSQIP) database, Youngerman and colleagues additionally established the mFI-11 as an independent predictor of 30-day adverse postoperative outcomes among brain tumor patients. Such outcomes included mortality, severe medical complications, prolonged length of stay, and unfavorable discharge. ${ }^{11}$ Our present study further underscores the effectiveness of the $\mathrm{mFI}-11$ in predicting postoperative mortality among brain tumor patients.

\section{5-Factor Modified Frailty Index}

The 5-factor modified frailty index (mFI-5) was developed from the mFI-11 after removal and changes to variables within the NSQIP database in 2012 made accurate use of the mFI-11 unfeasible. Subramaniam and colleagues compared the predictive ability of both indices for mortality, postoperative infection, and unplanned 30-day readmission in surgical patients and found that the mFI-11 and mFI-5 scores were equally effective predictors among all subspecialties that they investigated. ${ }^{6}$ Studying the mFI-5 as a continuous variable and examining neurosurgical procedures specifically, the investigators found that an incremental increase in the $\mathrm{mFI}-5$ score was significantly associated with mortality in both bivariate (OR 23.06, $\mathrm{p}<0.0001, \mathrm{CI} 14.38-35.97)$ and multivariate (OR 5.03, $\mathrm{p}<0.0001$, CI 2.95-8.58) analysis. ${ }^{6}$ Traven et al. applied the mFI-5 to predict morbidity and mortality following primary hip and knee arthroplasty. Using logistic regression models for multivariate analyses, Traven et al. found that, for every 1-point increase in mFI-5 score, there was a significant increase in the incidence of 30-day 
TABLE 5. Studies examining cranial neurosurgical patient outcomes using the $\mathrm{CCl}$ and the $\mathrm{mFI}-11$

\begin{tabular}{|c|c|c|c|c|c|}
\hline \multicolumn{3}{|c|}{$\mathrm{CCl}$} & \multicolumn{3}{|c|}{$\mathrm{mFI}-11$} \\
\hline Authors \& Year & Patient Population & Findings & Authors \& Year & Patient Population & Findings \\
\hline $\begin{array}{l}\text { Grossman et } \\
\text { al., } 2011^{12}\end{array}$ & $\begin{array}{l}4907 \text { pts w/ } \\
\text { metastatic brain } \\
\text { tumors, mean } \\
\text { age } 72.1 \text { yrs }\end{array}$ & $\begin{array}{l}\text { Greater CCI score associ- } \\
\text { ated w/ increased odds } \\
\text { of death, longer hospital } \\
\text { LOS, \& higher hospital } \\
\text { charges }\end{array}$ & $\begin{array}{l}\text { Cloney et al., } \\
2016^{25}\end{array}$ & $\begin{array}{l}243 \text { geriatric glioblastoma } \\
\text { pts (mean age } 73.1 \mathrm{yrs} \text { ) } \\
\text { w/ craniotomy for lobar } \\
\text { resection }\end{array}$ & $\begin{array}{l}\text { Pts w/ craniotomy for glio- } \\
\text { blastoma resection, frailty } \\
\text { (mFI-11) w/ less aggres- } \\
\text { sive intervention, longer } \\
\text { hospital LOS, \& increased } \\
\text { complications }\end{array}$ \\
\hline $\begin{array}{l}\text { Grossman et } \\
\text { al., } 2011^{22}\end{array}$ & $\begin{array}{l}5717 \text { pts w/ } \\
\text { intracranial me- } \\
\text { ningioma, mean } \\
\text { age } 73.6 \text { yrs }\end{array}$ & $\begin{array}{l}\text { Greater } \mathrm{CCl} \text { score associ- } \\
\text { ated w/ greater odds of } \\
\text { postop complications }\end{array}$ & $\begin{array}{l}\text { Youngerman } \\
\text { et al., } \\
2018^{11}\end{array}$ & $\begin{array}{l}9149 \text { pts underwent neuro- } \\
\text { surgical oncology proce- } \\
\text { dures, } 2070(22.6 \%)<45 \\
\text { yrs, } 1905(20.8 \%) 45-54 \\
\text { yrs, } 2420(26.5 \%) 55-64 \\
\text { yrs, \& } 2754(30.1 \%) \geq 65 \\
\text { yrs old }\end{array}$ & $\begin{array}{l}\text { Higher mFI-11 score inde- } \\
\text { pendently associated w/ } \\
\text { increased mortality, severe } \\
\text { medical \& neurologic } \\
\text { complications, any compli- } \\
\text { cations, prolonged LOS, \& } \\
\text { unfavorable discharge }\end{array}$ \\
\hline $\begin{array}{l}\text { Ening et al., } \\
\qquad 2015^{1}\end{array}$ & $\begin{array}{l}233 \mathrm{pts} \text { w/ glioblas- } \\
\text { toma, median } \\
\text { age } 62 \text { yrs }\end{array}$ & $\begin{array}{c}\mathrm{CCl} \text { score }>3 \text { significantly as- } \\
\text { sociated w/ poor overall \& } \\
\text { progression-free survival }\end{array}$ & $\begin{array}{l}\text { Imaoka et al., } \\
2018^{5}\end{array}$ & $\begin{array}{l}156 \mathrm{pts} w / \text { op for intracere- } \\
\text { bral hemorrhage, mean } \\
\text { age } 66 \text { yrs }\end{array}$ & $\begin{array}{l}\text { Higher mFI-11 score signifi- } \\
\text { cantly associated w/ unfa- } \\
\text { vorable postop outcome \& } \\
\text { increased mortality }\end{array}$ \\
\hline $\begin{array}{l}\text { O'Neill et al., } \\
2019^{23}\end{array}$ & $\begin{array}{l}123 \text { pts w/ } 131 \\
\text { unruptured } \\
\text { intracranial an- } \\
\text { eurysms, mean } \\
\text { age } 70.6 \text { yrs }\end{array}$ & $\begin{array}{l}\mathrm{CCl} \text { score independently } \\
\text { predicted poor treatment } \\
\text { outcome at discharge }\end{array}$ & $\begin{array}{l}\text { Mclntyre et } \\
\text { al., } 2019^{27}\end{array}$ & $\begin{array}{l}217 \text { aSAH pts, mean age } \\
57.6 \text { yrs }\end{array}$ & $\begin{array}{l}\text { mFI- } 11 \text { score } \geq 2 \text { significantly } \\
\text { associated w/ worse aSAH } \\
\text { grade, more complications, } \\
\text { \& increased mortality in } \\
\text { univariate but not multivari- } \\
\text { ate analysis }\end{array}$ \\
\hline $\begin{array}{l}\text { Schipmann et } \\
\text { al., } 2019^{24}\end{array}$ & $\begin{array}{l}2623 \text { brain \& spinal } \\
\text { tumor pts w/ } \\
\text { mean age } 55.29 \\
\text { yrs }\end{array}$ & $\begin{array}{l}\text { CCl score not correlated w/ } \\
\text { 30-day rates of un- } \\
\text { planned reops, unplanned } \\
\text { readmissions, or postop } \\
\text { mortality but significantly } \\
\text { associated w/ surgical site } \\
\text { infection rate }\end{array}$ & $\begin{array}{l}\text { Mclntyre et } \\
\text { al., } 2020^{26}\end{array}$ & $\begin{array}{l}75 \text { pts w/ angiogram- } \\
\text { negative SAH, mean age } \\
55.4 \text { yrs }\end{array}$ & $\begin{array}{l}\text { mFl-11 score } \geq 1 \text { indepen- } \\
\text { dently predicted increased } \\
\text { mortality \& lower score } \\
\text { predicted discharge home }\end{array}$ \\
\hline- & - & - & $\begin{array}{l}\text { Kim et al., } \\
2020^{21}\end{array}$ & $\begin{array}{l}248 \text { pts w/ sICH, mean age } \\
\quad 68.5 \text { yrs }\end{array}$ & $\begin{array}{l}\text { mFI-11 score not indepen- } \\
\text { dently associated w/ in- } \\
\text { creased mortality or worse } \\
\text { outcomes in pts w/ sICH }\end{array}$ \\
\hline
\end{tabular}

aSAH = aneurysmal SAH; LOS = length of stay; pt = patient; SAH = subarachnoid hemorrhage.

mortality for both primary hip (OR 1.49, p < 0.001, CI $1.28-1.73)$ and knee (OR 1.57, p < 0.001, CI 1.34-1.84) arthroplasty. ${ }^{2}$ Within spine surgery, Weaver and colleagues demonstrated that higher mFI-5 scores were associated with increased postoperative complications and morbidity following elective lumbar fusions. While bivariate analysis demonstrated that stepwise increases in $\mathrm{mFI}-5$ scores to 1 and $\geq 2$ compared to 0 were significantly associated with 30 -day mortality $(\mathrm{p}=0.003)$, the significance of these results did not hold in multivariate analysis. ${ }^{7}$ Thus, our findings are in line with the existing literature in concluding that the mFI-5 score is an effective predictor of postoperative mortality. Though there have been many studies examining cranial neurosurgical patient outcomes using both the CCI and the mFI-11 (Table 5), to our knowledge, the present study is the first to investigate the mFI-5's utility in predicting postoperative outcomes within this specific patient population. . $^{1,511,12,20-27}$

\section{Results of Our Study}

Given the relative ease of use of the mFI-5, our current study aimed to quantify the utility of the new mFI-5 relative to the established but more complex CCI and mFI-11 in predicting 90-day postoperative mortality among brain tumor patients. Given the significant correlation of these indices with each other via Spearman's rho $(\mathrm{p}<0.01)$ as well as the fact that there was no significant difference in the predictive ability of the mFI-5 index compared with that of either the CCI or the mFI-11, our results demonstrate that the mFI-5 is similar to the CCI and mFI-11 in effectively predicting postoperative mortality in our sample of brain tumor patients. The c-statistics for our adjusted models are above 0.7, emphasizing their strong predictive value. ${ }^{6}$ It is important to note that a likely reason why the CCI was not statistically significant in our logistic regression model (which included age as a covariate) is that the CCI weighted score is calculated using a patient's 
age, and therefore it would not be expected that the index should predict 90-day postoperative mortality independently of age. Our hypothesis was confirmed when, upon removing age as a covariate in our model, CCI became an independent predictor of 90-day postoperative mortality. When age is not included as a covariate in multivariate analysis, our results regarding the CCI and postoperative mortality concur with those of Ening et al. and Nuño et al., who both found that greater CCI scores were associated with significantly poorer progression-free survival and mortality among patients with brain tumors. ${ }^{1,14}$ Additionally, our study results obtained using the mFI-5 align with the conclusion of Youngerman et al. that the mFI-11 is an effective predictor of postoperative complications among brain tumor patients. ${ }^{11}$

Given the lower number of factors needed to calculate the $\mathrm{mFI}-5$ and its comparable predictive value relative to $\mathrm{mFI}-11$ and CCI, the mFI-5 may be a more practical choice for predicting postoperative mortality in a clinical setting where collection of fewer health variables is likely easier and more resource efficient. As discussed by Searle et al., frailty, though measured through a myriad of factors and indices, may represent a unique biological characteristic, independent of age and uniquely predictive of surgical morbidity and mortality. ${ }^{10}$ Although the CCI, mFI-11, and mFI-5 are broadly composed of different factors, we demonstrate that they similarly predict 90 -day postoperative mortality among brain tumor patients. The mFI-5 has potential to be commonly utilized in preoperative evaluations for patients with brain tumors due to its relative simplicity and predictive strength compared to more complex indices whose numerous factors may be more difficult for clinicians to obtain quickly and easily.

\section{Study Limitations}

There are various limitations to our study. Our study is retrospective and thus would benefit from validation with a study prospectively investigating the use of the $\mathrm{CCI}, \mathrm{mFI}-11$, and $\mathrm{mFI}-5$ in predicting postoperative complications and mortality. The retrospective nature of the present study also prevents us from commenting on causal relationships that might exist between preoperative comorbidities and postoperative patient outcomes. Additionally, given that we only reviewed patients from a single institution, further study of the association between CCI, mFI-11, and $\mathrm{mFI}-5$ with postoperative patient outcomes in a larger, multicenter cohort would serve to strengthen our conclusions. Nonetheless, given these limitations, our rigorous statistical analysis of a large cohort of 1692 brain tumor patients appears to demonstrate the utility of the mFI-5 as a predictor of 90-day postoperative mortality within this patient population.

\section{Conclusions}

In our cohort of 1692 brain tumor patients, the CCI, mFI-11, and mFI-5 are all similarly effective predictors of postoperative mortality following surgery. Considering its relative simplicity and predictive power in comparison to more complex indices requiring the collection of additional patient health variables, the mFI-5 may serve as an ef- fective and efficient tool for the preoperative stratification of patients with primary brain tumors to identify the most ideal surgical candidates.

\section{References}

1. Ening G, Osterheld F, Capper D, et al. Charlson comorbidity index: an additional prognostic parameter for preoperative glioblastoma patient stratification. J Cancer Res Clin Oncol. 2015;141(6):1131-1137.

2. Traven SA, Reeves RA, Sekar MG, et al. New 5-factor modified frailty index predicts morbidity and mortality in primary hip and knee arthroplasty. J Arthroplasty. 2019;34(1): 140-144.

3. Ali R, Schwalb JM, Nerenz DR, et al. Use of the modified frailty index to predict 30-day morbidity and mortality from spine surgery. J Neurosurg Spine. 2016;25(4):537-541.

4. Robinson TN, Eiseman B, Wallace JI, et al. Redefining geriatric preoperative assessment using frailty, disability and co-morbidity. Ann Surg. 2009;250(3):449-455.

5. Imaoka Y, Kawano T, Hashiguchi A, et al. Modified frailty index predicts postoperative outcomes of spontaneous intracerebral hemorrhage. Clin Neurol Neurosurg. 2018;175: 137-143.

6. Subramaniam S, Aalberg JJ, Soriano RP, Divino CM. New 5 -factor modified frailty index using American College of Surgeons NSQIP data. J Am Coll Surg. 2018;226(2):173-181. e8.

7. Weaver DJ, Malik AT, Jain N, et al. The modified 5-item frailty index: a concise and useful tool for assessing the impact of frailty on postoperative morbidity following elective posterior lumbar fusions. World Neurosurg. 2019;124:e626e632.

8. Lakomkin N, Zuckerman SL, Stannard B, et al. Preoperative risk stratification in spine tumor surgery: a comparison of the modified Charlson Index, Frailty Index, and ASA score. Spine (Phila Pa 1976). 2019;44(13):E782-E787.

9. Chaichana KL, Chaichana KK, Olivi A, et al. Surgical outcomes for older patients with glioblastoma multiforme: preoperative factors associated with decreased survival. $J$ Neurosurg. 2011;114(3):587-594.

10. Searle SD, Mitnitski A, Gahbauer EA, et al. A standard procedure for creating a frailty index. BMC Geriatr. 2008;8:24.

11. Youngerman BE, Neugut AI, Yang J, et al. The modified frailty index and 30-day adverse events in oncologic neurosurgery. J Neurooncol. 2018;136(1):197-206.

12. Grossman R, Mukherjee D, Chang DC, et al. Predictors of inpatient death and complications among postoperative elderly patients with metastatic brain tumors. Ann Surg Oncol. 2011; 18(2):521-528

13. Wahl TS, Graham LA, Hawn MT, et al. Association of the modified frailty index with 30-day surgical readmission. JAMA Surg. 2017;152(8):749-757.

14. Nuño M, Carico C, Mukherjee D, et al. Association between in-hospital adverse events and mortality for patients with brain tumors. J Neurosurg. 2015;123(5):1247-1255.

15. Rolston JD, Han SJ, Lau CY, et al. Frequency and predictors of complications in neurological surgery: national trends from 2006 to 2011. J Neurosurg. 2014;120(3):736-745.

16. Tsiouris A, Hammoud ZT, Velanovich V, et al. A modified frailty index to assess morbidity and mortality after lobectomy. J Surg Res. 2013;183(1):40-46.

17. Obeid NM, Azuh O, Reddy S, et al. Predictors of critical care-related complications in colectomy patients using the National Surgical Quality Improvement Program: exploring frailty and aggressive laparoscopic approaches. J Trauma Acute Care Surg. 2012;72(4):878-883.

18. Charlson ME, Pompei P, Ales KL, MacKenzie CR. A new method of classifying prognostic comorbidity in longitudinal 
studies: development and validation. J Chronic Dis. 1987; 40(5):373-383.

19. Gani F, Canner JK, Pawlik TM. Use of the Modified Frailty Index in the American College of Surgeons National Surgical Improvement Program database: highlighting the problem of missing data. JAMA Surg. 2017;152(2):205-207.

20. Missios S, Bekelis K. Drivers of hospitalization cost after craniotomy for tumor resection: creation and validation of a predictive model. BMC Health Serv Res. 2015;15(1):85.

21. Kim MG, Gandhi C, Azizkhanian I, et al. Frailty and spontaneous intracerebral hemorrhage: does the modified frailty index predict mortality? Clin Neurol Neurosurg. 2020;194: 105816.

22. Grossman R, Mukherjee D, Chang DC, et al. Preoperative Charlson comorbidity score predicts postoperative outcomes among older intracranial meningioma patients. World Neurosurg. 2011;75(2):279-285.

23. O'Neill AH, Chandra RV, Slater LA, et al. Influence of comorbidities on treatment of unruptured intracranial aneurysms in the elderly. J Clin Neurosci. 2019;62:38-45.

24. Schipmann S, Varghese J, Brix T, et al. Establishing riskadjusted quality indicators in surgery using administrative data-an example from neurosurgery. Acta Neurochir (Wien). 2019;161(6):1057-1065.

25. Cloney M, D'Amico R, Lebovic J, et al. Frailty in geriatric glioblastoma patients: a predictor of operative morbidity and outcome. World Neurosurg. 2016;89:362-367.

26. McIntyre M, Gandhi C, Dragonette J, et al. Increasing frailty predicts worse outcomes and increased complications after angiogram-negative subarachnoid hemorrhages. World Neurosurg. 2020;134:e181-e188.
27. McIntyre MK, Gandhi C, Long A, et al. Age predicts outcomes better than frailty following aneurysmal subarachnoid hemorrhage: a retrospective cohort analysis. Clin Neurol Neurosurg. 2019;187:105558.

\section{Disclosures}

Dr. Brem reports being a consultant for AsclepiX Therapeutics, StemGen, InSightec, Accelerating Combination Therapies, Camden Partners, LikeMinds, Inc., Galen Robotics, Inc., NexImmune, and Nurami Medical and receiving support of non-study-related clinical or research effort overseen by the author from Arbor Pharmaceuticals, Bristol-Myers Squibb, and Acuity Bio Corp.

\section{Author Contributions}

Conception and design: Khalafallah. Acquisition of data: Khalafallah, Huq. Analysis and interpretation of data: Khalafallah, Huq. Drafting the article: Khalafallah, Jimenez. Critically revising the article: all authors. Reviewed submitted version of manuscript: all authors. Approved the final version of the manuscript on behalf of all authors: Mukherjee. Statistical analysis: Khalafallah, Huq, Jimenez. Study supervision: Brem, Mukherjee.

\section{Correspondence}

Debraj Mukherjee: Johns Hopkins University School of Medicine, Baltimore, MD.dmukher1@jhmi.edu. 